\title{
THE RESEARCH OF MICRO-HARDNESS OF SIDE SURFACES OF TEETH CYLINDRICAL WHEELS PROCESSED BY "SHAVER-ROLLING DEVICE"
}

\author{
K. T. Sherov ${ }^{1 *}$, B. T. MARdonov ${ }^{2}$, T. M. BuZAuOVA ${ }^{1}$, \\ S. O. TUSSUPOVA ${ }^{1}$, N. S. SMAKOVA ${ }^{1}$, A. S. IZOTOVA ${ }^{1}$, \\ R. GABDYSSAlik ${ }^{3}$, T. B. KuRMANGALIYEV ${ }^{3}$, D. E. Elemes ${ }^{3}$ \\ ${ }^{1}$ Karaganda State Technical University, \\ 100027, B. Mira str. 56, Karaganda, Kazakhstan \\ ${ }^{2}$ Nawaii State Mining Institute, \\ 210100, st. Galaba shokh 170, Navoi city, Uzbekistan \\ ${ }^{3}$ D. Serikbaev East Kazakhstan State Technical University, \\ 070004, St. Protozanova A.K., 69, Ust-Kamenogorsk, Kazakhstan
}

[Received: 16 April 2019. Accepted: 03 February 2020] doi: 10.7546/JTAM.50.20.01.05

\begin{abstract}
This article presents the results of the study of micro-hardness on the end surface along the involute tooth profile after processing with a rolling tool. The results of the study showed that the value of micro hardness obtained by processing with "shaver-rolling device" made of steel R6M5 is obtained within HB 263-271, and when processed with using "shaver-rolling device" made of ShH15 steel within HB 274-276. The results of experimental studies have shown that with an increase in cutting speed, the micro-hardness of the side and main working surfaces of the teeth wheel decreases. The most favorable results were obtained when processing tools is made of steel ShH15 at cutting conditions: $n=100-400 \mathrm{rpm} ; S=0.2 \mathrm{~mm} /$ rotation.
\end{abstract}

KEY WORDS: rolling tool, micro-hardness, roughness, shaver-rolling device, cylindrical teeth wheel.

\section{The Relevance of THE RESEARCH}

In many industries, such as the production of heavy, mining, and mineral processing equipment in the manufacture of drive units, teeth wheels are widely used. It is known that teeth wheels are characterized not only by the complexity of the geometric shape, but also by the interdependence of dimensional parameters that must be performed with high accuracy even for non-critical gears. Therefore, in their manufacture the most time-consuming and responsible specific operation is the process of shaping the teeth. When shaping the teeth of gears, the main role is played by the methods of final processing.

\footnotetext{
*Corresponding author e-mail: shkt1965@mail.ru
} 
The studies [1-3] showed that the current state of the engineering industry, in particular the production of gears, dictates the need to develop and implement an advanced technological equipment, cutting tools and high-performance, resourcesaving machining technologies. Despite the continuous improvement of technological processes for the manufacture of gears, the labor intensity of gear formation operations remains very high and makes up to $50-60 \%$ of the total labor intensity of machining teeth wheels $[4,5]$.

Ensuring the required high accuracy and quality of machining teeth wheels is achieved by improving the technology of their manufacture.

To solve this problem, a resource-saving method and design of a tool ("shaverrolling device") have been developed for the final processing of the straight teeth of cylindrical wheels.

Figure 1 shows the process of machining gear teeth with a shaver-rolling device tool.

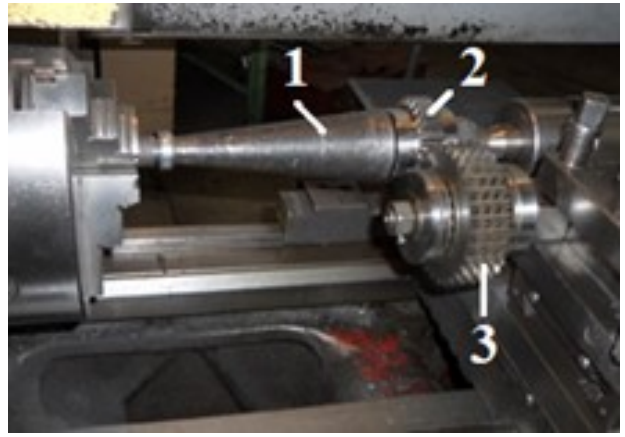

(a)

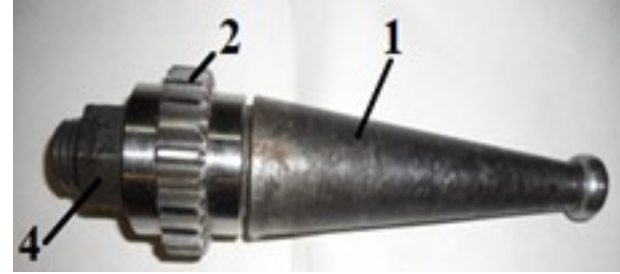

(b)

Fig. 1. The manufacturing process of the teeth wheel by "shaver-rolling device" tool: (a) processing; (b) blank mounted on the mandrel assembly; 1 - mandrel for the blank installation; 2 - blank; 3 - shaver-rolling device ShR15.

A special mandrel was made to install the blank (see Fig. 1b). The tooth wheel 2 is in backlash-free mesh with the shaver-rolling device 3 (see Fig. 1a).

When processing with "shaver-rolling device" for completeness of the evaluation the properties of the final state of the contact surfaces of the teeth, micro hardness studies on various parts of the side surfaces are of undoubted interest. In connection with this, the study of the micro hardness of the lateral surfaces of the teeth of cylindrical teeth wheels during the processing with a "shaver-rolling device" is an urgent task. 


\section{Methods and Equipment of the Research}

The research methodology is generally based on the scientific position of such sciences as the theory of metals and alloys, metal technology, materials science and metallography. The study of micro hardness on the side working surfaces of the tooth was carried out according to the previously developed method $[6,7]$.

The device PMT-3M was used in determining of the micro hardness. Metallographic studies were performed using a modular optical microscope Olympus SZX10. The microstructures of the samples were examined using a metallographic microscope LOMO METAM PB-21.

Figure 2 shows the instruments used in the study.

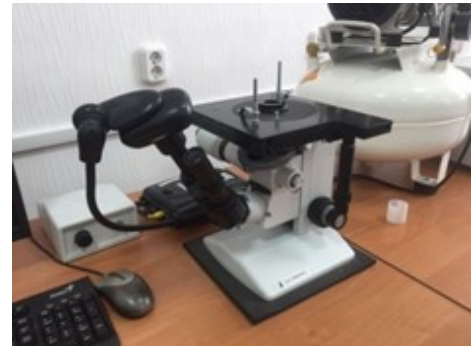

(a)

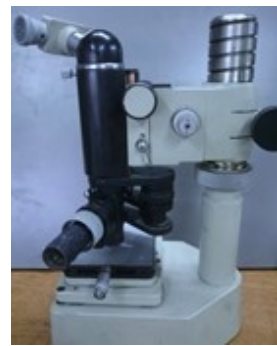

(b)

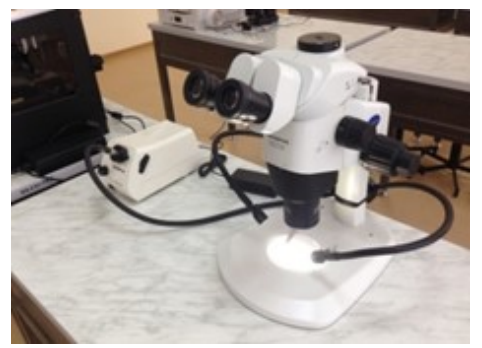

(c)

Fig. 2. Instruments used in the study: (a) metallographic microscope LOMO METAM PB-21; (b) the device PMT-3M; (c) modular optical microscope Olympus SZX10.

\section{Micro-Hardness Studies And Discussion of the Results}

Studies of the micro-hardness of the side surfaces of the teeth were carried out on cylindrical teeth wheels ( $m=3 \mathrm{~mm}, z=24)$, made of improved $40 \mathrm{X}$ steel with a hardness of $240 \ldots 280 \mathrm{HB}$. Processing was carried out with the use of shaver-rolling device of steel R6M5 and ShR15, with a constant delivering $S=0.1 \mathrm{~mm} /$ rotation at cutting speeds in the range of $200 \div 400 \mathrm{rpm}[8,9]$.

The scheme for measuring the microhardness $H_{\mu}$ on the microsections of the working surfaces of the tooth is shown in Fig. 3.

Micro-hardness measurements were carried out on the working surfaces of tooth $C$ and $B$. On the surface $C$, measurements were taken in three parallel locations with a center distance of $3 \mathrm{~mm}$ and measurements started at a distance of $0.5 \mathrm{~mm}$ from surface $A$.

In this case, the step of the measured points is $0.95 \mathrm{~mm}$ and the number of points is 20 (in all three places there are only 60).

At surface $B$, micro-hardness was measured in two parallel locations at a distance 


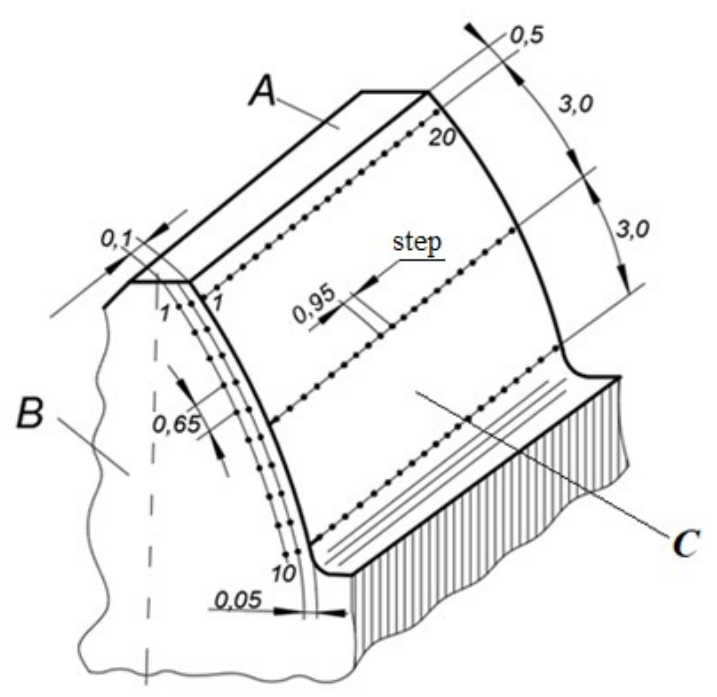

Fig. 3. Micro-hardness measurement scheme.

from the surface $C 0.05 \mathrm{~mm}$ and $0.1 \mathrm{~mm}$. The number of measured points is 10 (only 20 in two places), the spacing between measured points is $0.65 \mathrm{~mm}$.

Based on the obtained results, graphs of micro-hardness distribution on the end surface along the involute tooth profile and on the working surface of the tooth were formed. Figure 4 shows a graph of the distribution of micro-hardness on the end surface along the involute tooth profile.

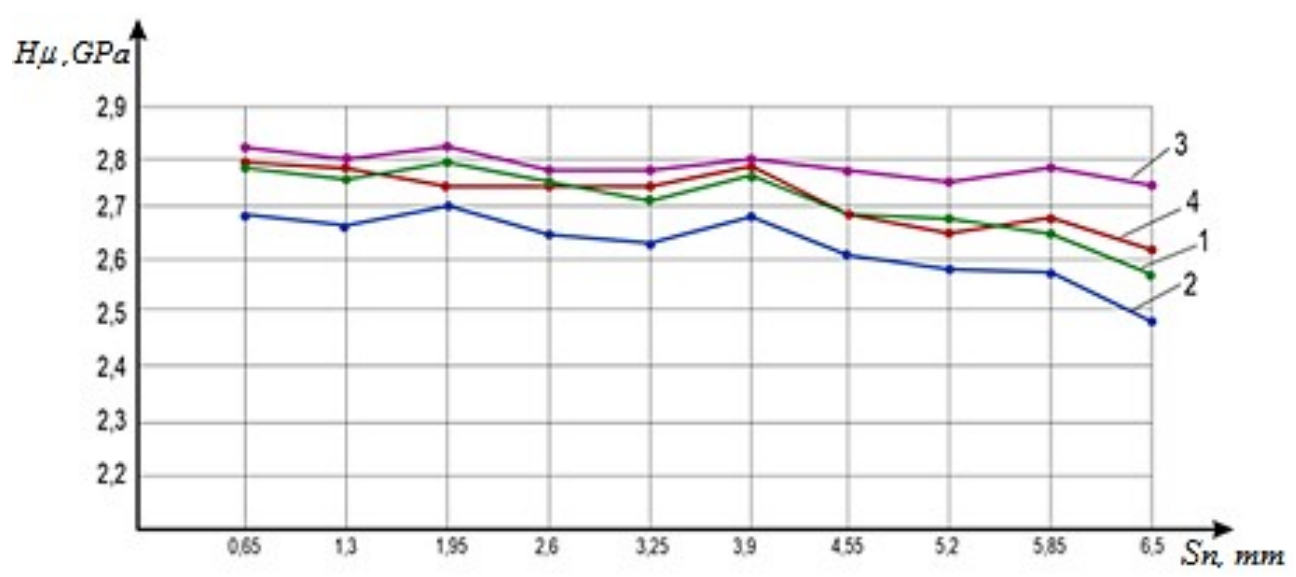

Fig. 4. Graph of micro-hardness distribution on the end surface along the involute tooth profile: 1 - R65, $0.05 \mathrm{~mm} ; 2$ - R65, $0.1 \mathrm{~mm} ; 3$ - ShH 15, $0.05 \mathrm{~mm} ; 4$ - SHh15, $0.1 \mathrm{~mm}$. 


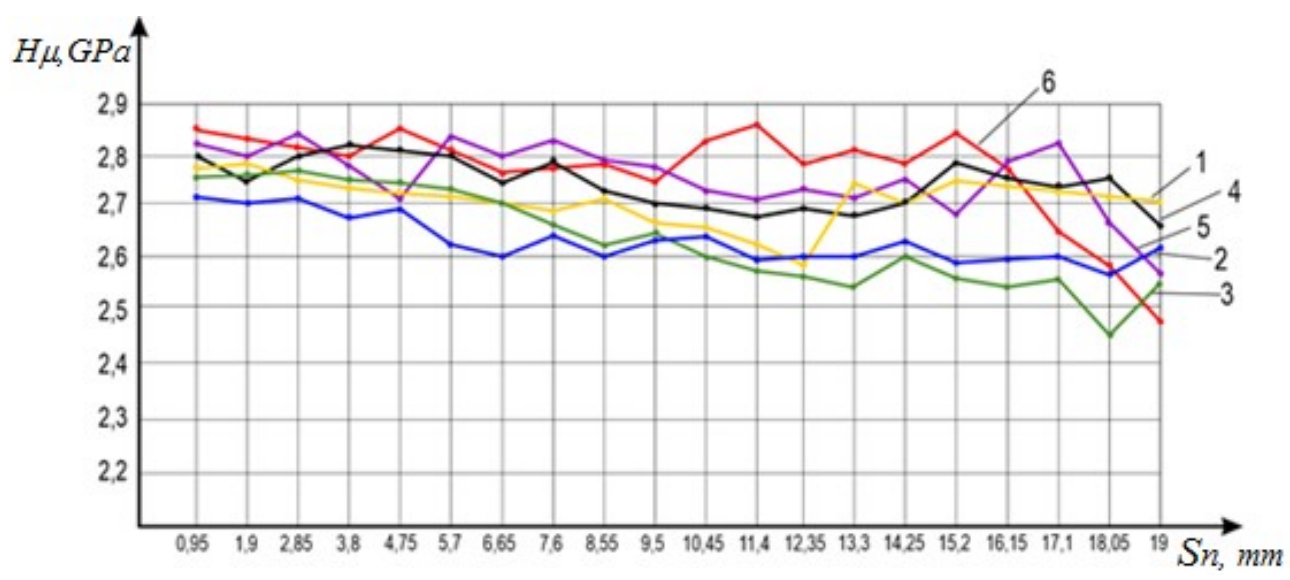

Fig. 5. Graph of the distribution of micro-hardness on the working side surface of the tooth: 1 - R65, 0.5 mm; 2 - R65, 3.5 mm; 3 - R65, 6.5 mm; 4 - ShH15, 0.5 mm; 5 - ShH 15, $3.5 \mathrm{~mm}$; 6 - ShH 15, $6.5 \mathrm{~mm}$.

Figure 5 shows a graph of the distribution of micro-hardness on the working side surface of the tooth. The results of the micro-hardness study on the working surface $\mathrm{B}$ of the teeth wheel (see Fig. 4) showed that when machining using a shaver-rolling device made of steel R6M5, the micro-hardness value is obtained within HB 248-279 made of steel ShH15 within HB 261-282. The average value of micro-hardness is in the range of 263-279.

The results of the micro-hardness study on the working surface $\mathrm{C}$ of the teeth wheel (see Fig. 5) showed that when machining with the shaver- rolling device of steel R6M5, the value of the micro-hardness is obtained within HB 263-271, the shaver-rolling device made of steel ShH15 within HB 274-276. The average value of micro-hardness is in the range of 263-276.

When machining with both tools, the micro-hardness values of the side and main working surfaces of the tooth of the teeth wheel satisfy. It should be noted that when processing with the use the shaver-rolling device made of steel ShH15, on the side and the main working surface of the teeth wheel, a more solid and hardened layer of the surface was obtained. Figure 6 shows a graph of the effect of cutting speed on the micro-hardness of the machined surface of the teeth of the wheels.

The results of experimental studies have shown that with an increase in cutting speed, the micro-hardness of the side and main working surfaces of the teeth wheel decreases (see Fig. 6).

The most favorable results were obtained when processing tools are made of steel ShH15 (see Fig. 6, straight 3) with cutting conditions: $n_{\mathrm{sp}}=100-400 \mathrm{rpm} ; S=$ $0.2 \mathrm{~mm} /$ rotation [10]. 


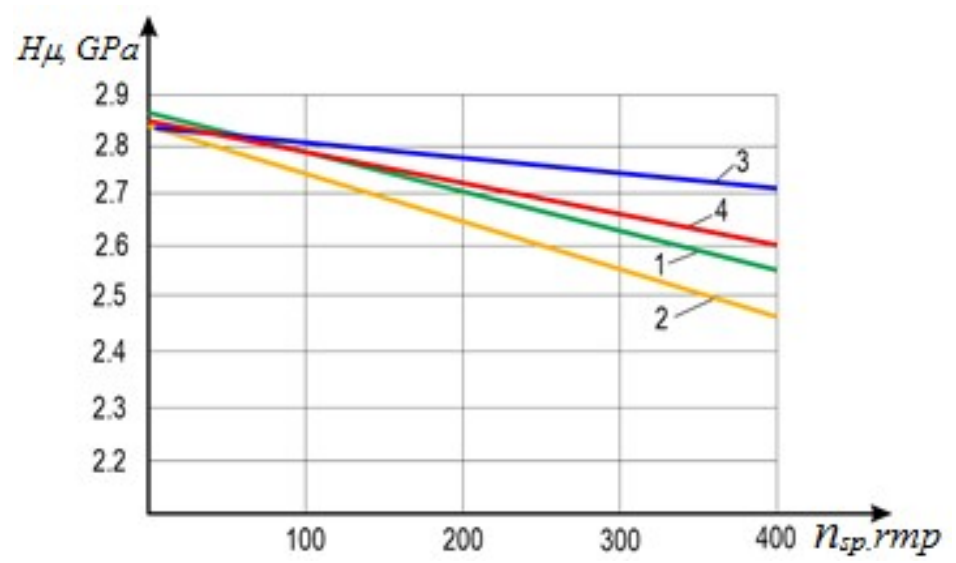

Fig. 6. The graph shows the effect of cutting speed on the micro-hardness of the machined surface of the teeth of the wheels: $1-\mathrm{R} 65, S=0.2 \mathrm{~mm} /$ rotation; $2-\mathrm{R} 65$, $S=0.1 \mathrm{~mm} /$ rotation; $3-\mathrm{ShH} 15, S=0.2 \mathrm{~mm} /$ rotation; $4-\mathrm{ShH} 15, S=0.1 \mathrm{~mm} /$ rotation.

\section{CONCLUSIONS}

1 The results of micro-hardness study on the end surface along the involute tooth profile showed that when machining using a shaver-rolling device made of steel R6M5, the micro-hardness value is obtained within HB 248-279, and when machining with a shaver-rolling device made of steel ShH15 within HB 261-282. The average value of micro-hardness is in the range of 263-279.

2. The results of the micro-hardness study on the working side surface of the tooth showed that when processing using a shaver-rolling device made of steel R6M5, the value of micro-hardness is obtained within HB 263-271, and when processed using a shaver-rolling device made of steel ShH15 within HB 274-276. The average value of micro-hardness is in the range of 263-276.

3. It has been established that when machining using "shaver-rolling device" made of steel ShH15, a more solid and hardened layer of the surface was obtained on the side and main working surface of the teeth wheel. The optimal cutting conditions are determined: $n_{\mathrm{sp}}=100-400 \mathrm{rpm} ; S=0.2 \mathrm{~mm} /$ rotation.

4. It has been established that an increase in cutting speed negatively affects the micro-hardness of the side and main working surfaces of the teeth wheel, and a decrease results in an increase in surface roughness.

\section{REFERENCES}

[1] D.E. Alikulov, B.T. Mardonov, A. Irzayev, B.K. Shakulov (2008) Improving the efficiency of cutting cylindrical teeth wheels. Mining Bulletin of Uzbekistan (4) 92-93. 
[2] B.T. MARDONOV (2017) Investigation of the error of the main parameters of cylindrical teeth wheels by cutting with a rolling tool (shaver-rolling device). Mining Bulletin of Uzbekistan (1) 95-97.

[3] K.T. Sherov, A.V. Mazdubai, A.K. Sherov, G. Tattimbek, N.B. Tulieva (2014) Methods of manufacturing large-modulus teeth wheels. In: University Proceedings. Karaganda: Publishing house of KSTU 57(4) 12-14.

[4] S.N. Kalashnikov, A.S. Kalashnikov (1986) "The manufacture of teeth wheels". Higher School, Moscow.

[5] V.I. Golikov (1998) Manufacturing technology of precise teeth wheels. Mechanical engineering, Moscow.

[6] E.V. Skribanov (1990) Precision control of kinematic chains of tooth-cutting machines and teeth gears. E.V. Skribanov, V.N. Yenin, I.E. Markov, Bulletin of mechanical engineering 9 49-51.

[7] A.A. Malikov, A.V. Sidorkin, A.S. YAmnikov (2011) "Innovative technologies for processing teeth of cylindrical wheels: a monograph". Tula: Publishing House of TSU.

[8] B.T. MARDONOV (2017) Investigation of the error of the main parameters of cylindrical teeth wheels by cutting with a rolling tool (shaver-rolling device). Mining Bulletin of Uzbekistan (1) 95-97.

[9] B.T. MARDONOV (2017) The investigation of precision of installation pieces of cylindrical gears in the process of rolling gear shaving. International Journal of Scientific \& Engineering Research 8(5) 1205-1207.

[10] B.T. MARDONOV (2018) "Experimental study of the teeth wheels processing with a shaver-wheel rolling tool / Mechanics and technology". Taraz: Publishing house "Taraz University" TarGU them. M.H. Dulati. (3) 64-71. 